\title{
Information Structural Notions and the Fallacy of Invariant Correlates
}

\author{
Caroline Féry \\ University of Potsdam
}

\begin{abstract}
In a first step, definitions of the irreducible information structural categories are given, and in a second step, it is shown that there are no invariant phonological or otherwise grammatical correlates of these categories. In other words, the phonology, syntax or morphology are unable to define information structure. It is a common mistake that information structural categories are expressed by invariant grammatical correlates, be they syntactic, morphological or phonological. It is rather the case that grammatical cues help speaker and hearer to sort out which element carries which information structural role, and only in this sense are the grammatical correlates of information structure important. Languages display variation as to the role of grammar in enhancing categories of information structure, and this variation reflects the variation found in the 'normal' syntax and phonology of languages.
\end{abstract}

\section{Introduction}

This paper has two aims. First section 2 gives an overview of the following notions of information structure: all-new, eventive, givenness, narrow focus, parallel focus, association with focus, verum focus, aboutness topic, framesetting topic and familiarity topic. The second aim is to show that these notions have no designated or invariant correlates in the grammar. The grammatical correlates which are usually assumed in the literature are quite diverse and concern different parts of grammar. One of these correlates is the initial, preverbal or postverbal position in the sentence (section 3). Another one associates special accents with information structure, for instance falling for focus and rising for topic (section 4). Alternatively, and more simply, these

Interdisciplinary Studies on Information Structure 6 (2007): 161-184

Féry, C., G. Fanselow and M. Krifka (eds.):

The Notions of Information Structure

C)2007 Caroline Féry 
correlates have been identified as the accented parts of the sentence (section 5). Following Schwarzschild's (1999) proposal, deaccenting could be the most relevant phonological correlate of information structure, signaling givenness (section 6). And, in some analyses, foci and topics may trigger an obligatory special phrasing, which requires a prosodic phrase (p-phrase) boundary to its left or to its right. A given constituent, by contrast, could be obligatorily dislocated, as has been claimed for Romance languages (section 7). The last correlate of information structure which has been assumed to be obligatory in certain languages is the presence of special morphemes. A focus is then accompanied by a so-called 'focus marker,' and a topic by a 'topic marker' (section 8). If, as is claimed in this paper, there are no designated or obligatory correlates of information structure, the phonetic, phonological, syntactic and morphological cues accompanying the information structural categories only help to highlight or to background constituents. The correlates themselves are independent syntactic or phonological features of the language which may improve speech processing in general, but are not necessarily associated with information structure. All features accompanying foci or topics also have roles which have nothing to do with information structure, and inversely, a topic or a focus can be left unrealized, or be realized in different ways. In other words, pitch accents, word order, cleft formation, dislocation, focus movement and morphological markers cannot be definitional for notions such as topic and focus, but they can be helpful in assigning a particular information structural role to a constituent.

\section{Definitions}

The notions of information structure (IS) are ambivalent (see Kuno 1972, Prince 1981, Lambrecht 1994 and many others). On the one hand, they denote extralinguistic cognitive or 'mental states' of referents, actions, locations, and 
temporality; on the other hand, they refer to the formal and communicative aspects of language, thus the way these concepts are implemented in grammar.

Addressing the extralinguistic function first, Chafe (1976) speaks about 'information packaging' and considers hypotheses about the receiver's assumptions as crucial to discourse structure. These are hypotheses about the status of the referent of each linguistic expression, as represented in the mind of the receiver at the moment of utterance. Prince (1981) defines information structure (packaging of information) in the following way:

The tailoring of an utterance by a sender to meet the particular assumed needs of the intended receiver. That is, information packaging in natural language reflects the sender's hypotheses about the receiver's assumptions and beliefs and strategies.

The notion of Common Ground, introduced by Stalnaker (1974), has been central in many subsequent theories of information structure, as it shapes the background to which new information is added (see Krifka, this volume). The Common Ground is the knowledge which the speaker assumes to be shared by herself and her interlocutor at the moment of utterance.

For Clark \& Haviland (1977), given is "information [the speaker] believes the listener already knows and accepts as true," and new is "information [the speaker] believes the listener does not yet know."

These cognitive and extralinguistic aspects of information structure are very important as they shape the grammatical devices implementing them, but they are not part of linguistics in the strict sense. They participate in the definitions of the categories entering the grammar of information structure in linguistics. In the following, we concentrate on the linguistic aspects of 
information structure, i.e., the way the information is transmitted through grammar.

As regards the implementation of the concepts of information structure in grammar, I assume the following notions to be crucial: all-new, eventive, given, focus, and topic. Focus is a cover term for a number of categories, of which narrow focus, parallel focus, association with focus and verum focus must be distinguished. Topic also groups different uses and concepts of this term: aboutness, frame-setting and familiarity are three basic partitions of topics.

\subsection{All-new}

An all-new sentence is one in which all parts are newly introduced into the discourse at the moment of utterance. This kind of sentence has been called 'wide or broad focus' or 'out-of-the-blue' sentences. Typical for them is the fact that no constituent has been previously introduced into the discourse, and that they are uttered in an informational vacuum, as far as the common ground is concerned. One can think of them as sentences in a laboratory situation, where an informant reads a contextless sentence from a computer screen. Another place of appearance is the beginning of radio or television news, where the speaker cannot elaborate on an assumed common ground with the audience. Allnew sentences can be 'eventive' or have a topic-comment structure.

\subsection{Eventive}

Eventive sentences introduce a whole event and contrast in this way with topiccomment sentences. Lambrecht (1994) discusses the difference between the two at length with an example such as (1).

(1) My car broke down. 
In the eventive reading, this sentence is an explanation for a behavior, a delay or the like and has only one pitch accent on car. The sentence is not necessarily understood as a predication about the car, but rather the fact that the car is broken down is taken as a single event. In the topic-comment reading, my car is first introduced into the discourse, and carries a pitch accent as a topic. In a second step, the information that it is broken down is added, and is typically focused. It receives an accent of its own. The result is a sentence with two pitch accents. Longer eventive sentences may be indistinguishable from topiccomment sentences because a longer predicate receives a pitch accent by the rules regulating the location of normal sentence accents.

\subsection{Given}

A given constituent has already been introduced into the discourse by a previous utterance or question, or is somehow prominent in the common ground. The notion of givenness has been attributed a formal status by Schwarzschild (1999), who claims that a given constituent is one which is entailed by the preceding discourse. This use of givenness is restricted to text-givenness (previously mentioned in the discourse), as opposed to context-givenness (contextually salient). In frameworks in which mental states of constituents are definitional for linguistic categories, as for Prince (1981) and Lambrecht (1994) for example, this notion is sometimes called 'topic.' As will be shown below, I take topic to be a different category from givenness.

\subsection{Narrow focus}

When part of the sentence is given, there is a division of the sentence into the given part (sometimes called 'background') and the informationally focused part, the part of the sentence which is highlighted relative to this background. 'Focus' is used rather traditionally as the part of the sentence which introduces 
alternatives (Rooth 1985, 1992, Krifka, this volume). Besides the normal semantic value present in each expression, a 'focus semantic value' is a facultative additional value, understood as a set of alternatives, that is, a set of propositions which potentially contrast with the ordinary semantic value. The ordinary semantic value is always contained in this set. The term 'focus' is thus restricted here to constituents which are informationally more important than other backgrounded parts of the same sentence. As a result, an all-new sentence typically contains no focus. In the general case, it also does not trigger a set of alternatives, though the possibility of focusing a whole sentence should not be excluded on principled grounds.

\subsection{Parallel focus}

The term 'parallel focus' is chosen to avoid 'contrastive focus,' which has been used in many different senses in the literature. Parallel focus refers to the part of the sentence which is compared and elicited from a pair (or a triplet or more) of similar elements. It comprises 'selectional,' 'alternative,' 'corrective,' and the like, in which two (or more) terms are explicitly mentioned and somehow compared with each other. Right node raising and gapping constructions are constructions containing explicit parallel elements. But the parallel elements do not need to be expressed: they can also arise from the context. A narrow and a parallel focus may appear in the same sentence, as shown by Selkirk (this volume). It is assumed that a parallel focus is in a sense to be defined stronger than a narrow focus, which is itself stronger than a part of an all-new sentence (see below).

\subsection{Association with focus}

The term 'association with focus' refers to focus particles obligatorily associated with a focused domain. These constructions have truth values, as opposed to 
narrow focus. As demonstrated by Rooth (1985) sentences (2a) and (2b) are not interchangeable in all contexts. Small capitals indicate pitch accents.

(2) a. Mary Ann only gave ice-cream to her DAUGHTER.

b. Mary Ann only gave ICE-CREAM to her daughter.

In the simple case illustrated in (2), the focus operator takes as its domain the accented element, and eliminates all other candidates in the alternative sets, other children in (2a) and other food items in (2b). Thus the accented element behaves like a narrow focus, with the difference that it is further restricted by an overt operator. Association with focus is a particular case of focus since the focus particle does not exclusively associate with a focus, but has a meaning of its own, like additive, restrictive and scalar. That the domain of these particles is signaled with a pitch accent in languages like German and English is not surprising, given the role of pitch accents in these languages, but it does not necessarily have to be done this way. It could also be marked with adjacency or by a specialized morpheme, as in other languages.

\subsection{Verum focus}

Verum focus is a further special case of narrow focus, namely on the affirmative part of a declarative sentence (Höhle 1992). Since there is no morpheme specialized for this task, a (possibly default) accent on the finite part of the predicate fulfills this function in languages with lexical accents, like German and English. In an embedded sentence, the complementizer may carry the accent, as in (3):

(3) DASs gestreikt wird, ist klar.

'It is clear that a strike will take place.' 
An interesting fact about verum focus is that all other constituents in the same clause have to be given and deaccented, since any other accent would just cancel out the illocutionary function of this accent.

\subsection{Aboutness topic}

An 'aboutness topic' is a referent which the remainder of the sentence is about, possibly contrasting with other referents under dispute, and crucially followed by a focus constituent (see Reinhart 1981 and Jacobs 2001, among others). The topic element has often, but not necessarily, been previously introduced into the discourse. This category also includes 'contrastive topics' (see the articles by Endriss \& Hinterwimmer and Zimmermann in this volume, as well as Tomioka, to appear). A distinction must be made between 'topic' as an information structural concept and 'topicalization', which is a syntactic operation consisting of moving a constituent to the beginning of a sentence. The two concepts often go hand in hand, but this is not necessarily the case.

\subsection{Frame-setting topic}

A frame-setting topic gives a frame in which the remainder of the sentence is to be interpreted. It is very common in so-called 'topic languages.' Examples are 'Berlin, I live in Schöneberg' or 'As for health, Peter is in great form.' See also the example in (4) from Japanese, a topic language.

\subsection{Familiarity topic}

The term 'topic' also refers to elements in the background, which are supposed to be salient in the consciousness of the protagonists. Since this is a very different concept from that introduced in 2.8 and 2.9, where the topic is prominent and accented, I will ignore this meaning of the term in the discussion of the grammatical correlates of the concepts. 


\section{Focus and Topics as Positions in the Sentence}

It is conspicuous that topics are usually sentence-initial. Halliday (1967-8), for instance, claims that the initial position is a necessary condition for a 'theme' (a topic). This preferred place for a topic is easily explained from a functional perspective: since it is the element about which the remainder of the sentence makes a comment, it certainly is reasonable to introduce it right at the beginning of the sentence. Moreover, a topicalized element is often realized as a separate iphrase (intonation phrase), and initiality allows a clear intonational separation. But a topic is not necessarily located sentence-initially. In the following Japanese sentence (4), the topic dezaato-wa 'dessert' is placed after a quantifier phrase and is thus not initial. ${ }^{1}$ A subscript $\mathrm{P}$ shows a prosodic phrase (p-phrase), and a subscript I an intonation phrase (i-phrase).

$$
\begin{aligned}
& \left((\text { Daremo-ga })_{\mathrm{P}}(\text { dezaato-wa })_{\mathrm{P}}(\text { aisu-o }\right. \\
& \text { everyone-NOM dessert-TOP ice-cream-ACC ate } \left.\left.)_{\mathrm{P}}\right)_{\mathrm{I}} . \quad \text { (Japanese }\right) \\
& \text { 'As for dessert, everyone ate ice cream.' }
\end{aligned}
$$

At best, a strong preference for placing topics at the beginning of a sentence can be observed, and the reason for this, as already mentioned, may be purely functional. A similar case can be made for givenness: If, as in (5), an element is given or expresses an afterthought, it is preferable to place it in a position where prominence is poorest. A final dislocated element is deaccented and possesses no phonological prominence. This is illustrated with 'anti-topics' in Cantonese (5a) and French (5b). ${ }^{2}$

\footnotetext{
Thanks to Shin Ishihara for his help with Japanese. See also Tomioka (to appear).

2 See also Frey (2004), who finds contrastive topics in the middle field in German.
} 
(5) a. ((Go loupo $)_{\mathrm{P}}$ (nei gin-gwo gaa $\left.)_{\mathrm{P}},(\text { ni go namjange })_{\mathrm{P}}\right)_{\mathrm{I}}$. (Cantonese) CLF wife 2.SG see-EXP PTC thisCLF man MDF

'The wife you have seen, of this man.'

b. ((Pierre l'a mangée $)_{\mathrm{P}}$, (la pomme $\left.)_{\mathrm{P}}\right)_{\mathrm{I}}$.

(French)

Peter it-ACC has eaten, theapple

'Peter has eaten the apple.'

Focus has also been associated with special focus positions in certain languages. Hungarian has been described as a language which obligatorily places an exhaustive focus preverbally (É. Kiss 1998, this volume), while Italian has been analyzed as a language with clause-initial (Rizzi 1997) or clause-final (SamekLodovici 2006) foci. Aghem has been analyzed as a language with a postverbal focus position called IAV for 'immediately after the verb' (see Horváth 1986 for this strong claim). It is to be noticed that 'dedicated' focus positions are sometimes defined structurally or linearly, but that in-depth analyses seem to prefer a linear definition.

An alternative explanation, which accounts for the Hungarian facts without forcing an association between focus and preverbal position, can be stated in the following way: Hungarian is a left-headed language, both at the level of the p-word and at the level of the p-phrase. Focus wants to be prominent and the preferred stress position is at the beginning of the main i-phrase, directly after the topic, which forms an independent i-phrase, and thus does not count as the leftmost position for the remainder of the sentence. The initial position is occupied by the narrow focus, as often as possible, and happens to be the verb in all other cases (see Szendrői 2003, who gives a syntactico-phonological account of the information structural facts of Hungarian). But focus may also be located postverbally. In (6), both the VP and Mary are focused and Peter is given, but 
the indirect object, which carries a narrow focus embedded in the VP (my analysis), is postverbal. Small caps indicate stress.

(6) ((Tegnap este $\left.)_{\mathrm{P}}\right)_{\mathrm{I}}\left((\text { BEMUTATtAM Pétert })_{\mathrm{P}} \quad(\text { MARINAK })_{\mathrm{P}}\right)_{\mathrm{I}}$. yesterday evening PRT-introduced-I Peter-ACC Mary-DAT

'Yesterday evening, I introduced Peter to Mary.'

(Hungarian)

In Italian, as in other Romance languages, given elements may be moved away from the matrix clause, and, in many cases, it is this movement which causes finality of focus; see (7), adapted from Samek-Lodovici (2006). Italian is a language with final stress, both at the level of the p-word and at the level of the p-phrase, and syntactic reorganization helps prosody in moving narrow foci to the furthest possible rightward position. Thus, both in Hungarian and in Italian the peripheral position of focus is not a special feature of focus, but a general preference for prominence.

(7) $\left.\quad\left((\text { L'ho incontrato a PARIGI })_{\mathrm{P}} \text {, (Luigi }\right)_{\mathrm{P}},(\text { ieri })_{\mathrm{P}}\right)_{\mathrm{I}}$.

(Italian)

(I) him have-met in Paris, Luigi, yesterday

'I met Luigi in Paris yesterday.'

As for Aghem, Hyman \& Polinsky (to appear) claim that the IAV position is not reserved for focus, and that focus is not necessarily in the IAV position. In their analysis, some constituents appear obligatorily in this position independently of their focused or non-focused status. The preference for this position is explained by binding facts.

In sum, topics and foci may preferably occupy sentence positions in which general properties of the language allow them to carry prominence. But this is always a tendency which optimizes communication, and arises from independent properties, like accent position preferences, binding and scope relationships. 


\section{Bearers of Special Accents}

Bolinger (1958) introduced a distinction between accent A, a falling accent, and accent B, a fall-rise accent, and Jackendoff (1972) and Liberman \& Pierrehumbert (1984) related the former to focus and the latter to topic, as in (8). Manny has accent B, and Anna accent A.

\{What about Manny? Who did he come with?\} $\left((\mathrm{MANNY})_{\mathrm{P}}(\text { came with ANNA })_{\mathrm{P}}\right)_{\mathrm{I}}$.

Büring (2003), for German, and Steedman (2000), for English, establish an obligatory relationship between contours and roles by having pitch accent contours participate in the definition of topics and foci. Attempts to relate forms of accents to specific information structural roles are found for other languages as well. For instance, Frota (2000) claims that narrow foci in Portuguese are always associated with a certain kind of accent. In the same way, Baumann (2006) and Baumann \& Grice (2006) relate the form of accents to givenness in German.

However, in view of the facts, the relation between topics, foci or givenness and special contours is at best unstable, and I would say untenable. ${ }^{3}$ The lack of necessary association between accents and roles can be illustrated with examples in which different kinds of accents are used for topics and foci from those which have been proposed in the literature. Consider (9), which elicits a double focus in German. The answer to a double wh-question can

3 Some excellent works propose a pragmatic relationship between tones and meanings, like 'assertiveness' or 'statementhood' (L-) and 'concessive continuation dependence' (H\%) (Bartels 1997), and 'newness' $\left(\mathrm{H}^{*}\right)$, 'prominent, but not part of the predication' $\left(\mathrm{L}^{*}\right)$ or 'elements in a scale, but not part of the predication' $\left(\mathrm{L}^{*}+\mathrm{H}\right)$ (Pierrehumbert \& Hirschberg 1990). Marandin et al. (2005) relate the melody of final contours in French to the hearer's revision as anticipated by the speaker. These authors have in common that they refrain from associating tones with information structural roles like topic and focus. 
consist of a single-pair answer, and I assume that this is the case in (9). The second focus, den Dekan, has a falling contour as it is the last accent in the sentence. But the first focus, die Präsidentin, has a rising contour without necessarily being a topic. This contour arises because in a sequence of two accents, the first one has a rising and the second one a falling contour, independently of the role of the constituent. See also Hörnig \& Féry (2007), who show with spontaneous data that the direction of pitch accents as falling or rising is a function of the position of the constituent in the sentence rather than of its informational role.

(9) \{Wer hat wen gesehen?\}

$\left.\left((\text { Die PRÄSIDENTIN })_{\mathrm{P}} \text { (hat den DEKAN gesehen }\right)_{\mathrm{P}}\right)_{\mathrm{I}}$.

(German) the president has the dean seen

'The president has seen the dean.'

As far as topics are concerned, the preference for sentence-initiality is paired with a preference for rising tones. The rising tone is just a reflex of the nonfinality of this accent.

To sum up this section, topics and foci have been analyzed by some linguists as the bearers of obligatory special contours. But the necessity of this relationship is not firmly established, and in fact, there are numerous counterexamples showing that other accents can do the job in some contexts. In German, a focus usually has a falling contour because it is the last accent in the sentence, and the tone of a topic is rising because it is not the final accent. Again, the preference for associating some specific contours with information structural roles can be explained by general properties of the language. 


\section{Bearers of Accents}

The preceding section has shown that there is no necessary relation between focus/topic on the one hand and special contours on the other. A concomitant question bears on the necessity of accents (and of deaccenting) in general in relation to focus/topic/givenness. Jackendoff formulates a rule which relates a focus with an accent. 'If a phrase $\mathrm{P}$ is chosen as the focus of a sentence $\mathrm{S}$, the highest stress in $\mathrm{S}$ will be on the syllable of $\mathrm{P}$ that is assigned highest stress by the regular stress rules' (1972:247). Nearly all models relating focus with phonology rely on a direct correspondence between semantics and phonetics and require an accent signaling the presence of a focused constituent (see for instance Cinque 1993, Reinhart 1981, Rooth 1985, 1992, Selkirk 1995, 2002, 2006, Schwarzschild 1999, Truckenbrodt 1999, Zubizaretta 1998 and many others). ${ }^{4}$

There are systematic exceptions to this rule, like the numerous tone and phrase languages ${ }^{5}$ which do not use accents at all. As an example, Xu (1999) shows that focus in Mandarin Chinese raises the pitch range of a focused word, and compresses the postfocal domain, but Mandarin has no pitch accent in the usual sense of this term.

The crucial question, however, is whether languages with pitch accents necessarily use them for topics and foci, or whether there are exceptions. And in fact, there are a whole range of examples in which the association between focus and accent seems to be cancelled. One type of example is the so-called Second

4 And nearly all models suggest that the correspondence between semantics and phonology goes through the intermediary of so-called F-marks, which signal focus in the syntax (Selkirk 1995, this volume, Schwarzschild 1999, Féry \& Samek-Lodovici 2006).

5 Many tone languages use $\mathrm{F}_{0}$ only for lexical tone distinctions, or increase or decrease the pitch ranges used in prosodic domains, but do not associate prominent syllables with special, pragmatically induced meanings, as is the case for pitch accents (see Hartmann, this volume). 
Occurrence Focus (SOF, see Partee 1999, Rooth 2004, Beaver et al. 2007, Féry $\&$ Ishihara 2005, to appear), which combines elements of association with focus and givenness. Only vegetables in (10b) is associated with the focus operator only, and is thus a focus, but it is also given, because it is repeated from (10a). The example comes from Partee (1999).

(10) a. $\left\{\right.$ Everyone already knew that Mary only eats $\left.[\text { vegetables }]_{\mathrm{F}}\right\} .($ English)

b. If even $[\mathrm{Paul}]_{\mathrm{F}}$ knew that Mary only eats [vegetables $]_{\mathrm{sOF}}$, then he should have suggested a different restaurant.

There are only weak correlates of accent, and no pitch excursions on postnuclear SOF, although according to Féry \& Ishihara (2005), a pitch accent is indeed present in the prenuclear position.

Other cases of absence of accent on a focus arise from stress-clash and the consequent deaccenting. In (11a), herself is a so-called intensifier which is claimed to be obligatorily accented in the literature. But in the presence of an adjacent narrow focus (association with focus), the accent on herself disappears. The same is true of the association with focus adjacent to a parallel focus in (11b), a sentence from Rooth (1992). In (11c), the answer to the question is completely deaccented. Instead the additive particle also carries the stress. (11d), a sentence from Reis \& Rosengren (1997), shows that a contrastive topic (Peter in Krifka's 1999 analysis) can also be realized without excursion if another, more prominent topic (Gauguin) is adjacent.

(11) a. Marie-Luise even grows RICE herself.

b. People who GROW rice only EAT rice. 
c. $\quad$ John said that Mark is coming, but what did Sue say?\}

She ALSO said that Mark is coming.

d. $\quad$ Boy, Paul possesses a Gauguin. $\}$

Einen GAUGUIN besitzt Peter AUCH

'Peter also owns a Gauguin'

In view of these examples, a strict and necessary association between focus and accent or topic and accent must be given up. Accent is a preferred option but it is not obligatory. It is only present if the phonological structure of the sentence allows it.

\section{Deaccenting}

If accent is not a reliable indicator of focus, could deaccenting the backgrounded part of the sentence be a better correlate of information structure? Givenness, like backgroundedness, is often indicated with lack of accent.

Immediate problems arise with this view. Givenness is not obligatorily associated with deaccenting, as shown in (12).

(12) a. $\quad$ Who was loved by two men, Audrey or Lucy?\}

(English)

b. It was LUCY.

In Schwarzschild's (1999) terminology, Lucy in (12b) is 'entailed' by the previous question. But the fact that it was Lucy (and not Audrey) who was loved by two men is not.

The second problem arising from an association of givenness with deaccenting is often a prosodic operation eliminating one of two adjacent accents, as illustrated in (11a-b). In short, deaccenting cannot be considered as 
uniquely expressing givenness (contra Selkirk 1995 and Schwarzschild 1999), and givenness cannot be assumed to always be accompanied by deaccenting.

\section{Obligatory Phrasing}

Prosodic phrasing has also been claimed to be an obligatory phonological indicator of focus. It is one of the most interesting aspects of the phonology of information structure, one of the reasons being its universality. No language can be said to lack prosodic phrasing. In the same way as our articulatory organs define and limit the segments we use in our inventories of sounds, our vocal tract is limited by air pressure and respiratory needs, which force the division of a long string of speech into smaller chunks of phrasing. And because these smaller prosodic chunks are compulsory, grammar uses them for its own needs and inserts breaks and tonal boundaries at syntactically and semantically relevant places, helping in this way both production and comprehension of speech. Another reason why prosodic phrasing requires our attention is that the syntactic reorganization of constituents in non-canonical word order, like clefting, dislocation, topicalization, scrambling, and so on, always goes together with reorganization of phonological phrasing.

The question that arises in the context of the present paper is whether prosodic phrasing is a necessary companion of information structure.

Beckman \& Pierrehumbert (1986) have been influential in claiming that in English and in Japanese, the absence of downstep (reflected in the boosting of the $\mathrm{F}_{0}$ associated with a high pitch accent) on a focused constituent is synonymous with an intermediate phrase boundary. In their approach, an intermediate phrase, which is a domain equivalent to the one which is called pphrase in this paper, is the domain in which downstep applies. If downstep (or catathesis, as they call the phenomenon) is interrupted, their model predicts an 
obligatory boundary to the next intermediate phrase. In Féry \& Ishihara (to appear), by contrast, prosodic phrasing is conditioned by syntactic structure, and only marginally by information structure. A higher pitch accent has no influence on phrasing.

However, it has been claimed that Chichewa, like other Bantu tone languages, inserts an obligatory right boundary after a focused constituent, separating the focused constituent from the rest of the sentence (see Kanerva 1990). In Chichewa, phrasing is realized by non-intonational means, like sandhi tones at the lexical level and segmental lengthening.

I cannot answer the question regarding obligatory phrasing for Bantu languages at present for lack of relevant data. It may well be the case that it is a strongly preferred way to show focus, as intonational separation is a strongly preferred way to indicate topic in German (see Jacobs 2001). But examples like (11d) are always possible, and Bantu languages may have similar examples.

\section{Morphological Markers}

Finally, it is claimed for a number of languages that a focus or a topic constituent is delimited by special markers. Examples appear in (4) for Japanese and in (5) for Cantonese. Further examples appear in (13) for Buli and (14) for Ditammari, both from Fiedler et al. (to appear). In Buli, the focus marker kà precedes the focused constituent. But when the focused túe is sentence-initial, the marker kà is not obligatory. As for Ditammari, the focus marker nya follows the focused constituent, but it also fulfills other functions, like gender agreement.

(13) Buli (Gur, Oti-Volta, Buli-Konni)

Q: What did the woman eat? 

A: ò yòb kà túé.
3.SG eat FM beans
'She ate BEANS.'

(14) Ditammari (Gur, Oti-Volta, Eastern)

Q: What did the woman eat?

A: ò dī yātũrà nyā.

3.SG eat beans FM

'She ate BEANS.'

It is typical for information structural markers to have other functions and meanings than purely that of a marker. Even the topic marker wa in Japanese has been shown to not be exclusively a topic marker.

\section{Conclusion}

This paper started with a series of definitions in the realm of information structure. New, eventive, given, narrow focus, parallel focus, association with focus, verum focus, aboutness topic, frame-setting topic and familiarity topic are the primary categories and concepts used in grammar. In the second part of the paper a common misconception has been demonstrated: that an information structural category needs to be associated with an invariant grammatical property. Though it is undeniable that phonological, syntactic and morphological cues are necessary for the implementation and signaling of information structure, it is not the case that any of these cues can ever be regarded as definitional for information structural categories. In other words, focus requires prominence, givenness requires lack thereof, and topics are preferably located in positions in which their processing is optimal. These are tendencies which are realized whenever they can be, but they need not be. All correlates of information structure also have other functions in grammar. In 
other words, focus, topic and givenness help themselves from the grammatical cues at their disposal, but none of them has the unique privilege of use of these cues.

\section{References}

Bartels, Christine. 1997. Towards a Compositional Interpretation of English Statement and Question Intonation. PhD Dissertation, University of Massachusetts, Amherst.

Baumann, Stefan. 2006. The Intonation of Givenness. Tübingen: Niemeyer.

Baumann, Stefan \& Martine Grice. 2006. The intonation of accessibility. Journal of Pragmatics 38, 1636-1657.

Beaver, David, Brady Zack Clark, Edward Flemming, T. Florian Jäger \& Maria Wolters. 2007. When semantics meets phonetics: Acoustical studies of second occurrence focus. Language 83, 245-276.

Beckman, Mary E. \& Janet B. Pierrehumbert. 1986. Intonational structure in Japanese and English. Phonology Yearbook 3, 255-309.

Bolinger, Dwight. 1958. A theory of pitch accent in English. Word 14, 109-149.

Büring, Daniel. 2003. On D-trees, beans, and B-accents. Linguistics and Philosophy 26, 511-545.

Chafe, Wallace. 1976. Givenness, contrastiveness, definiteness, subjects, topics, and point of view. In Subject and Topic, ed. Charles N. Li. New York: Academic Press, 25-55.

Cinque, Guglielmo. 1993. A null theory of phrase and compound stress. Linguistic Inquiry 24.2, 239-297.

Clark, Herbert H. \& Susan E. Haviland. 1977. Comprehension and the givennew contrast. In Discourse Production and Comprehension, ed. Roy O. Freedle. Hillsdale, NJ: Erlbaum, 1-40.

É. Kiss, Katalin. 1998. Identificational focus versus information focus. Language 74.2, 245-273. 
É. Kiss, Katalin. this volume. Topic and Focus: Two Structural Positions Associated with Logical Functions in the Left Periphery of the Hungarian Sentence

Endriss, Cornelia \& Stefan Hinterwimmer. This volume. Direct and Indirect Aboutness Topics.

Féry, Caroline \& Shinichiro Ishihara. 2005. Interpreting second occurrence focus. Ms. University of Potsdam.

Féry, Caroline \& Shinichiro Ishihara. To appear. How focus and givenness shape prosody. In Information Structure from Different Perspectives, eds. Malte Zimmermann \& Caroline Féry.

Féry, Caroline \& Vieri Samek-Lodovici. 2006. Focus projection and prosodic prominence in nested foci. Language 82.1, 131-150.

Fiedler, Ines, Katharina Hartmann, Brigitte Reineke, Anne Schwarz \& Malte Zimmermann. To appear. Subject focus in West African languages. In Zimmermann, Malte \& Caroline Féry, Eds. Information Structure in Different Perspectives.

Frey, Werner. 2004. A medial topic position for German. Linguistische Berichte 198, 153-190.

Frota, Sónia. 2000. Prosody and Focus in European Portuguese. New York: Garland Publishing.

Halliday, M. A. K. (1967-8) Notes on transitivity and theme in English. Journal of Linguistics 3 \& 4.

Hartmann, Katharina. This volume. Focus and Tone.

Höhle, Tilmann N. 1992. Über Verum-Fokus im Deutschen. In: Jacobs, Joachim (Ed.) Informationsstruktur und Grammatik. Linguistische Berichte, Sonderheft 4, 112-141.

Hörnig, Robin \& Caroline Féry. 2007. Describing altered spatial layouts. Ms. Potsdam.

Horváth, Júlia. 1986. Focus in the Theory of Grammar and the Syntax of Hungarian. Dordrecht: Foris. 
Hyman, Larry \& Maria Polinsky. to appear. Is there a focus position in Aghem? In: Zimmermann, Malte \& Caroline Féry, Eds. Information Structure in Different Perspectives..

Jackendoff, Ray. 1972. Semantic Interpretation in Generative Grammar. Cambridge, MA: MIT Press.

Jacobs, Joachim. 2001. The dimensions of topic-comment. Linguistics 39.4, 641-681.

Kanerva, Jonni M. 1990. Focusing on phonological phrases in Chichewa. In The Phonology-Syntax-Interface, eds. Sharon Inkelas \& Draga Zec. Chicago: University of Chicago Press, 145-161.

Krifka, Manfred. 1999. Additive particles under stress. Proceedings of SALT 8. Cornell, CLC Publications, 111-128.

Krifka, Manfred. This volume. Basic Notions of Information Structure.

Kuno, Susumu. 1972. Functional sentence perspective: A case study from Japanese and English. Linguistic Inquiry 3, 269-336.

Lambrecht, Knud. 1994. Information Structure and Sentence Form: Topic, Focus, and the Mental Representations of Discourse Referents. Cambridge: Cambridge University Press

Liberman, Mark \& Janet Pierrehumbert. 1984. Intonational invariance under changes in pitch range and length. In Language Sound Structure, eds. Mark Aronoff \& Richard T. Oehrle. Cambridge, MA: MIT Press, 157-233.

Marandin, Jean-Marie, Claire Beyssade, Elisabeth Delais-Roussarie, Annie Rialland \& Michel de Fornel. 2005. The meaning of final contours in French. Manuscript, CNRS and Université de Paris 7.

Partee, Barbara H. 1999. Focus, quantification, and semantics-pragmatics issues. In Focus: Linguistic, Cognitive, and Computational Perspectives, eds. Peter Bosch \& Rob van der Sandt. Cambridge: Cambridge University Press, 213-231.

Pierrehumbert, Janet \& Julia Hirschberg. 1990. The meaning of intonational contours in the interpretation of discourse. Intentions in communications, eds. Philip R. Cohen, Jerry Morgan \& Martha E. Pollack. Cambridge, MA: MIT Press, 271-311. 
Prince, Ellen F. 1981. Toward a taxonomy of given-new information. In Radical Pragmatics, ed. Peter Cole. New York: Academic Press, 223-256.

Reinhart, Tanya. 1981. Pragmatics and linguistics: An analysis of sentence topics. Philosophica 27, 53-94.

Reis, Marga \& Inger Rosengren. 1997. A modular approach to the grammar of additive particles: The case of German auch. Journal of Semantics 14, $237-$ 309.

Rizzi, Luigi. 1997. The fine structure of the left periphery. In Elements of Grammar: Handbook in Generative Syntax, ed. Liliane Haegeman, Dordrecht: Kluwer Academic Publishers, 281-337.

Rooth, Mats. 1985. Association with Focus. Doctoral Dissertation, University of Massachusetts, Amherst.

Rooth, Mats. 1992. A theory of focus interpretation. Natural Language Semantics 1, 75-116.

Rooth, Mats. 2004. Comments on Krifka's paper. In Context-Dependence in the Analysis of Linguistic Meaning, eds. Hans Kamp \& Barbara H. Partee. Amsterdam: Elsevier, 475-487.

Samek-Lodovici, Vieri. 2006. When right dislocation meets the left-periphery: A unified analysis of Italian non-final focus. Lingua 116, 836-873.

Schwarzschild, Roger. 1999. Givenness, AvoidF and other constraints on the placement of accent. Natural Language Semantics 7, 141-177.

Selkirk, Elisabeth O. 1995. Sentence prosody: Intonation, stress and phrasing. In Handbook of Phonological Theory, ed. John Goldsmith. Cambridge, MA: Blackwell, 550-569.

Selkirk, Elisabeth O. 2002. Contrastive FOCUS vs. presentational focus: Prosodic evidence from right node raising in English. In Speech Prosody 2002: Proceedings of the 1st International Conference on Speech Prosody, eds. Bernard Bel \& Isabel Marlin. Aix-en-Provence: Laboratoire Parole et Langage, 643-646.

Selkirk, Elisabeth O. 2006. The prosodic phrasing of FOCUS followed by focus: The case of English. In Tones and Tunes: Studies in Word and Sentence Prosody, eds. Carlos Gussenhoven \& Tomas Riad. Berlin: Mouton. 
Selkirk, Elisabeth O. This volume. Contrastive Focus, Givenness and the Unmarked Status of "Discourse-New".

Stalnaker, Robert. 1974. Pragmatic presuppositions. In Semantics and Philosophy, eds. Milton K. Munitz \& Peter K. Unger. New York: New York University Press, 197-214.

Steedman, Mark. 2000. Information Structure and the Syntax-Phonology Interface. Linguistic Inquiry 31, 649-689.

Szendröi, Kriszta. 2003. A stress-based approach to the syntax of Hungarian focus. The Linguistic Review 20 (1), 37-78.

Tomioka, Satoshi. To appear. In: Contrastive topics operate on speech acts. In: Zimmermann, Malte \& Caroline Féry, Eds. Information Structure in Different Perspectives.

Truckenbrodt, Hubert. 1999. On the relation between syntactic phrases and phonological phrases. Linguistic Inquiry 30:2, 219-255.

Xu, Yi. 1999. Effects of tone and focus on the formation and alignment of F0 contours. Journal of Phonetics 27, 55-105.

Zimmermann, Malte. This volume. Contrastive Focus.

Zubizaretta, Maria Luisa. 1998. Prosody, Focus and Word Order. Cambridge, MA: MIT Press.

Caroline Féry

Universität Potsdam

Department of Linguistics

Karl-Liebknecht-Str. 24-25

14476 Potsdam

Germany

caroline.fery@googlemail.com 